\title{
Troglitazone upregulates PTEN expression and induces the apoptosis of pulmonary artery smooth muscle cells under hypoxic conditions
}

\author{
WEI-FENG PI ${ }^{1 *}$, XUE-JUN GUO ${ }^{1 *}$, LI-PING SU ${ }^{2}$ and WEI-GUO XU ${ }^{1}$ \\ ${ }^{1}$ Department of Respiratory Medicine, Xinhua Hospital, School of Medicine, Shanghai Jiaotong University, \\ Shanghai, P.R. China; ${ }^{2}$ Division of Bioengineering, National University of Singapore, Singapore
}

Received April 26, 2013; Accepted July 15, 2013

DOI: $10.3892 /$ ijmm.2013.1487

\begin{abstract}
The increased proliferation and decreased apoptosis of pulmonary artery smooth muscle cells (PASMCs) are the main causes of hypoxic pulmonary hypertension. In this study, we investigated the role of troglitazone [peroxisome proliferator-activated receptor $\gamma$ (PPAR $\gamma$ ) agonist] in the regulation of phosphatase and tensin homologue deleted on chromosome 10 (PTEN) expression and the apoptosis of PASMCs under hypoxic conditions. Normal human PASMCs were cultured in growth medium (GM) and treated with troglitazone $(0.5-80 \mu \mathrm{M})$ under hypoxic conditions $\left(5 \% \mathrm{CO}_{2}+94 \%\right.$ $\mathrm{N}_{2}+1 \% \mathrm{O}_{2}$ ) for $72 \mathrm{~h}$. The gene expression of PTEN, AKT-1 and AKT-2 was determined by quantitative reverse transcription PCR (qRT-PCR). The protein expression level of PTEN, AKT and phosphorylated AKT (p-AKT) was determined by western blot analysis. The apoptosis of PASMCs was determined by measuring the activities of caspase-3, -8 and -9 and by TUNEL assay. The proliferation rate of the PASMCs was altered in a concentration-dependent manner by troglitazone. A significantly reduced proliferation rate was observed at troglitazone concentrations starting from $20 \mu \mathrm{M}$ under hypoxic conditions $(72 \pm 5.8 \%)$. Although the gene expression levels of PTEN were increased, the gene expression levels of AKT-1 and AKT-2 remained unaltered. Consistent with this, PTEN protein expression was also altered in a concentration-dependent manner by troglitazone. Although AKT expression was unaltered in all the cell samples, reduced p-AKT expression was observed in the troglitazone-treated PASMCs. Troglitazone increased the
\end{abstract}

Correspondence to: Professor Xue-Jun Guo or Professor Wei-Guo Xu, Department of Respiratory Medicine, Xinhua Hospital, School of Medicine, Shanghai Jiaotong University, 1665 Kongjiang Road, Shanghai 200025, P.R. China

E-mail: snowgen@126.com

E-mail: xuweiguo@xinhuamed.com.cn

${ }^{*}$ Contributed equally

Key words: smooth muscle cells, pulmonary artery hypertension, proliferation, peroxisome proliferator-activated receptor $\gamma$, apoptosis activities of caspase-3, -8 and -9 in the PASMCs. bpV(HOpic) (PTEN inhibitor) and GW9662 (PPAR $\gamma$ inhibitor) inhibited PTEN protein expression and recovered the proliferation rate of the PASMCs. TUNEL assay demonstrated that troglitazone significantly increased the apoptosis of PASMCs under hypoxic conditions. In conclusion, troglitazone increases PTEN expression under hypoxic conditions in a concentration-dependent manner. Troglitazone increases the apoptosis of PASMCs under hypoxic conditions. The increase in PTEN expression is mediated through the PPAR $\gamma$ signaling pathway.

\section{Introduction}

Hypoxic pulmonary hypertension (HPH) is an important pathophysiological process and plays a key role in the development of a variety of pulmonary diseases, including chronic obstructive pulmonary disease (COPD), pulmonary fibrosis and pulmonary heart disease. Multiple pathogenic pathways have been implicated in the development of HPH, including those at the molecular and genetic levels of smooth muscle and endothelial cells and adventitia. The HPH 'phenotype' is characterized by a decreased ratio of apoptosis/proliferation in pulmonary artery smooth muscle cells (PASMCs) and a thickened, disordered adventitia (1). The increased proliferation and reduced apoptosis of PASMCs is a component of pulmonary hypertension, increased pulmonary vascular resistance and pulmonary arterial pressure, which is associated with COPD and right ventricular failure (2). Since the proliferation of SMCs is an essential feature of vascular proliferative disorders, considerable efforts have been made to develop a therapeutic strategy that effectively suppresses SMC proliferation.

Peroxisome proliferator-activated receptor $\gamma$ (PPAR $\gamma)$ agonists act as negative regulators of SMC growth (3). They are potent inhibitors of vascular SMC proliferation in vitro and in vivo (3). PPAR $\gamma$ agonists can stimulate the production and secretion of apolipoprotein E (ApoE), which has antiproliferative effects on human PASMCs (4). Nisbet et al (5) found that rosiglitazone (a PPAR $\gamma$ agonist) attenuated hypoxiainduced pulmonary vascular remodelling and hypertension by suppressing oxidative and proliferative signals. These studies provide the mechanisms underlying the therapeutic effects of PPAR $\gamma$ activation in pulmonary hypertension. 
Studies have also suggested that PPAR $\gamma$ agonists upregulate phosphatase and tensin homologue deleted on chromosome 10 (PTEN) expression in allergen-induced asthmatic lungs (6). Zhang et al (7) demonstrated that rosiglitazone inhibits the migration of human hepatocellular BEL-7404 cells by upregulating PTEN. The tumor suppressor gene, PTEN, encodes a dual-specificity phosphatase that recognizes protein and phosphatidylinositol substrates and modulates cellular functions, such as migration and proliferation. However, the role of PPAR $\gamma$ in regulating PTEN expression in PASMCs under hypoxic conditions has not yet been elucidated. Therefore, the present study aimed to examine the molecular mechanisms through which PPAR $\gamma$ activation modulates PTEN expression in PASMCs under hypoxic conditions, since hypoxia is a proliferative stimulator of PASMCs (5).

In the present study, we investigated the effects of troglitazone (a PPAR $\gamma$ agonist) on PTEN gene expression and the apoptosis of PASMCs under hypoxic conditions. We found that troglitazone increased PTEN expression in PASMCs in a concentration-dependent manner and increased the apoptosis of PASMCs under hypoxic conditions.

\section{Materials and methods}

Cell culture of PASMCs. Human PASMCs were purchased from ScienCell Research Laboratories (Carlsbad, CA, USA). The PASMCs were cultured and expanded in SMC growth medium (GM): smooth muscle cell basal medium (BM; ScienCell Research Laboratories) supplemented with SMC growth supplement (ScienCell Research Laboratories), 10\% fetal bovine serum (FBS) and $1 \%$ penicillin/streptomycin $(\mathrm{P} / \mathrm{S})$. The cells were cultured at $37^{\circ} \mathrm{C}$ in a $5 \% \mathrm{CO}_{2}$ incubator, and the cell culture medium was changed every 2 days. Cells were regularly passaged every 4-5 days.

Hypoxia treatment. The PASMCs were cultured under hypoxic conditions in order to determine the anti-proliferative effects of troglitazone on PASMCs. A hypoxic environment for PASMC culture was created in an incubator: $5 \% \mathrm{CO}_{2}+94 \%$ $\mathrm{N}_{2}+1 \% \mathrm{O}_{2}$. The cells were collected for gene and protein expression experiments after $72 \mathrm{~h}$. Generally, the PASMCs were seeded in plates in BM overnight before being used in the experiments.

PASMC culture with PTEN inhibitor or PPAR $\gamma$ antagonist. The PASMCs were seeded at $1 \times 10^{4}$ cells/well in a 12 -well plate and cultured in GM supplemented with $2.5 \mu \mathrm{M}$ dipotassium bisperoxo(5-hydroxypyridine-2-carboxyl)oxovanadate (V) [bpV(HOpic)], a PTEN inhibitor, or $1 \mu \mathrm{M}$ 2-chloro-5-nitro-Nphenylbenzamide (GW9662), a PPAR $\gamma$ antagonist (both were purchased from EMD4Biosciences, Darmstadt, Germany). bpV(HOpic) and GW9662 were added to the cell culture medium $1 \mathrm{~h}$ prior to the addition of troglitazone. The PASMCs were cultured in an incubator under hypoxic conditions for $72 \mathrm{~h}$. Cell proliferation was determined using the CyQUANT ${ }^{\circledR}$ Cell Proliferation assay kit (Invitrogen, Carlsbad, CA, USA). Proteins were extracted from the treated cells using PhosphoSafe ${ }^{\mathrm{TM}}$ Extraction Reagent (EMD Millipore, Billerica, MA, USA). Following quantification, the proteins were used for western blot analysis.
Quantitative reverse transcription PCR ( $R$ RT-PCR) analysis. PASMCs were analyzed by qRT-PCR to determine gene expression at $0.5,1,2,4,8$ and $24 \mathrm{~h}$ after treatment with troglitazone. Total RNA was isolated as previously described (8). DNase I was used to remove DNA contamination. cDNA was synthesized using the Maxima ${ }^{\circledR}$ First Strand cDNA Synthesis kit (Fermentas, Hanover, MD, USA).

To quantify gene expression levels, Maxima ${ }^{\circledR}$ SYBR-Green qPCR Master Mix (2X) (Fermentas) was used. The qPCR thermal cycling protocol was programmed for 40 cycles: 1 cycle of initial denaturation for $10 \mathrm{~min}$, then denaturation at $95^{\circ} \mathrm{C}$ for $15 \mathrm{sec}$, annealing for $30 \mathrm{sec}$ and extension at $72^{\circ} \mathrm{C}$ for $30 \mathrm{sec}$. The primers used are listed in Table I.

Cell proliferation. PASMC proliferation was determined using the CyQUANT ${ }^{\circledR}$ Cell Proliferation assay kit (Invitrogen). Briefly, $1 \times 10^{4}$ PASMCs/well were seeded into 24-well plates and cultured with BM for $24 \mathrm{~h}$. The cell culture medium was changed to GM supplemented with various concentrations of troglitazone (stock solution $20 \mathrm{mM}$ in 100\% DMSO) for $72 \mathrm{~h}$ in an incubator under hypoxic conditions at $37^{\circ} \mathrm{C}$. Subsequently, the cell culture supernatant was removed. The cells were washed with PBS and frozen at $-80^{\circ} \mathrm{C}$ for $1 \mathrm{~h}$. Each well was then incubated with $200 \mu \mathrm{l} \mathrm{CyQUANT}{ }^{\circledR}$ cell-lysis buffer containing DNase-free RNase $(1.35 \mathrm{U} / \mathrm{ml})$ for $1 \mathrm{~h}$ at room temperature to eliminate the RNA component of the fluorescence signal. Subsequently, $200 \mu \mathrm{l}$ cell-lysis buffer containing $2 \mathrm{X}$ solution of CyQUANT ${ }^{\circledR}$ GR dye were added to each well for $10 \mathrm{~min}$. The fluorescence intensity was measured using a Tecan fluorescence microplate reader (Tecan Infinite M200 microplate reader; LabX, Canada) with $480 \mathrm{~nm}$ excitation and $520 \mathrm{~nm}$ emission.

Lactate dehydrogenase ( $L D H)$ release for cytotoxic determination. The cytotoxicity of troglitazone towards PASMCs was determined using CytoTox-ONE ${ }^{\mathrm{TM}}$ Homogeneous Membrane Integrity assay (Promega, Madison, WI, USA). Briefly, 5x10 PASMCs/well were cultured in a 12 -well plate with GM supplemented with troglitazone for $72 \mathrm{~h}$ under normoxic conditions at $37^{\circ} \mathrm{C}$. Subsequently, cell culture supernatant was collected and mixed with CytoTox-ONE ${ }^{\mathrm{TM}}$ Reagent for $20 \mathrm{~min}$. After the addition of stop solution, the fluorescence signal was measured at an excitation wavelength of $560 \mathrm{~nm}$ and an emission wavelength of $590 \mathrm{~nm}$.

Western blot analysis of PASMCs. Protein expression in the treated and non-treated PASMCs was determined by western blot analysis as previously described (9). Cells were lysed with PhosphoSafe $^{\mathrm{TM}}$ Extraction Reagent (EMD Millipore) and the protein concentration was determined using Bradford reagent (Bio-Rad Laboratories, Inc., Hercules, CA, USA).

Proteins were separated and electrophoretically blotted onto a nitrocellulose membrane. After washing with $10 \mathrm{mM}$ Tris/HCl wash buffer ( $\mathrm{pH} 7.6$ ) containing $0.05 \%$ Tween-20, the membrane was incubated in blocking buffer (5\% non-fat dry milk, $10 \mathrm{mM}$ Tris $\mathrm{pH}$ 7.5, $100 \mathrm{mM} \mathrm{NaCl}, 0.1 \%$ Tween20 ) for $3 \mathrm{~h}$ at room temperature. Subsequently, the blots were incubated with diluted primary antibodies: AKT $(1: 1,000)$, phosphorylated (Ser 473) AKT (p-AKT) (1:500), glyceraldehyde-3-phosphate dehydrogenase $(\mathrm{GAPDH})(1: 1,000)$ and 
Table I. Primers used for RT-PCR.

\begin{tabular}{|c|c|c|c|}
\hline Gene & Primer sequence & Annealing temp. $\left({ }^{\circ} \mathrm{C}\right)$ & Size (bp) \\
\hline GAPDH & $\begin{array}{ll}\text { Forward } & \text { 5'-AGCCACATCGCTCAGACAC-3' } \\
\text { Reverse } & \text { 5'-TAAAAGCAGCCCTGGTGAC-3' }\end{array}$ & 60 & 90 \\
\hline PTEN & $\begin{array}{l}\text { Forward 5'-TCACCAACTGAAGTGGCTAAAGA-3' } \\
\text { Reverse } \\
\text { 5'-CTCCATTCCCCTAACCCGA-3' }\end{array}$ & 60 & 155 \\
\hline AKT-1 & $\begin{array}{l}\text { Forward } 5 \text { '-TAACCTTTCCGCTGTCGC-3' } \\
\text { Reverse } \\
\text { 5'-ATGTTGTAAAAAAACGCCG-3' }\end{array}$ & 58 & 125 \\
\hline AKT-2 & $\begin{array}{ll}\text { Forward } & \text { 5'-GGTCGCCAACAGCCTCAA-3' } \\
\text { Reverse } & \text { 5'-CACTTTAGCCCGTGCCTTG-3' }\end{array}$ & 58 & 127 \\
\hline
\end{tabular}

RT-PCR, reverse transcription PCR; GAPDH, glyceraldehyde-3-phosphate dehydrogenase; PTEN, phosphatase and tensin homologue deleted on chromosome 10.

PTEN (1:200) (all purchased from Santa Cruz Biotechnology, Inc., Santa Cruz, CA, USA) overnight at $4^{\circ} \mathrm{C}$. Subsequently, anti-rabbit IgG conjugated with HRP (dilution, 1:3,000-1:8,000) was used to detect the binding of antibodies. The binding of the specific antibody was visualized using the SuperSignal Chemiluminescent Substrate kit and exposed to X-ray film (both from Pierce Biotechnology, Inc., Rockford, IL, USA).

Apoptosis assay. Proteins from the treated and non-treated PASMCs were used to determine the apoptosis of PASMCs by determining the activities of caspase- $3,-8$ and -9 .

Caspase- 3 and -8 activities were determined using caspase-3 and -8 assay kits, Fluorimetric (Sigma-Aldrich, Sigma, St. Louis, MO, USA). The fluorescence intensity of caspase-3 was recorded at a wavelength of $360 \mathrm{~nm}$ for excitation and a wavelength of $460 \mathrm{~nm}$ for emission, and that of caspase- 8 was recorded at an excitation of $360 \mathrm{~nm}$ and an emission of $440 \mathrm{~nm}$. The activity of caspase was calculated as fluorescence intensity $(\mathrm{FI}) / \mathrm{min} / \mathrm{ml}=\Delta \mathrm{Flt} /(\mathrm{t} \times \mathrm{v})$, where $\Delta \mathrm{Flt}$ is the difference in fluorescence intensity between time zero and time $t$ minutes; $t$ is the reaction time in min; and $\mathrm{v}$ is the volume of the sample in $\mathrm{ml}$.

Similarly, caspase-9 activity was determined using the caspase-9 assay kit, Fluorimetric (QIA72; EMD4Biosciences). The fluorescence intensity was recorded at a wavelength of $400 \mathrm{~nm}$ for excitation and a wavelength of $505 \mathrm{~nm}$ for emission. The same formula as the one used for the calculation of caspase-3 activity was used to calculate caspase- 9 activity.

TUNEL assay. To detect the apoptosis of PASMCs following treatment with troglitazone, the PASMCs were cultured in $\mathrm{BM}$ and incubated for $72 \mathrm{~h}$ under hypoxic conditions. TUNEL assay was performed using the In situ Cell Death Detection kit (Roche) as per the manufacturer's instructions. In brief, the cells were fixed with $4 \%$ paraformaldehyde for $20 \mathrm{~min}$ at $25^{\circ} \mathrm{C}$. After washing with PBS for $30 \mathrm{~min}$, the cells were incubated in permeabilization solution $(0.1 \%$ Triton $\mathrm{X}-100,0.1 \%$ sodium citrate) for $10 \mathrm{~min}$ at $4^{\circ} \mathrm{C}$. After washing, the cells were incubated with rabbit anti-calponin antibody overnight at $4^{\circ} \mathrm{C}$. On the second day, reaction mixture from the kit supplemented with goat anti-rabbit IgG conjugated with FITC was applied to the cells for $1 \mathrm{~h}$ at $37^{\circ} \mathrm{C}$ in the dark. The samples were counterstained with DAPI to visualize the nuclei after TUNEL staining. The apoptotic index was calculated as $\mathrm{TUNEL}^{+}$ cells/total cells/low magnification field.

Statistical analysis. All statistical analyses were performed using SPSS software (version 10.0). All experiments were performed at least 3 times. The data are presented as the means \pm standard error means (SEM) and analyzed with the method of analysis of variance (ANOVA) using the Bonferroni test. A Student's t-test was performed to determine statistical difference. All tests were performed with a significance level of $5 \%$.

\section{Results}

Toxicity of troglitazone towards PASMCs. The toxicity of troglitazone towards the cells was determined in order to exclude the possibility that the decrease in PASMC proliferation was due to the toxicity of troglitazone towards PASMCs. PASMCs were cultured in GM supplemented with troglitazone for $48 \mathrm{~h}$ in an incubator under normal conditions. The supernatant was collected to measure LDH concentration (an index of cell injury). Significant cell injury was only observed when the troglitazone concentration was increased up to 60 and $80 \mu \mathrm{M}$ (Fig. 1).

The percentage of LDH in the supernatant was $1.2 \pm 0.5 \%$ when the cells were cultured in GM without troglitazone, while it was $1.5 \pm 0.5 \%$ with $0.5 \mu \mathrm{M}$ troglitazone, $1.8 \pm 0.4 \%$ with $1 \mu \mathrm{M}, 2 \pm 0.4 \%$ with $2 \mu \mathrm{M}, 1.8 \pm 0.6 \%$ with $5 \mu \mathrm{M}, 2.1 \pm 0.5 \%$ with $10 \mu \mathrm{M}, 1.8 \pm 0.3 \%$ with $20 \mu \mathrm{M}, 2.1 \pm 0.5 \%$ with $40 \mu \mathrm{M}$, $3 \pm 0.8 \%$ with $60 \mu \mathrm{M}$ and $3.7 \pm 0.6 \%$ with $80 \mu \mathrm{M}$ troglitazone (Fig. 1). These results demonstrated that troglitazone was well tolerated by PASMCs.

Concentration-dependent effects of troglitazone on PASMC proliferation. The proliferation rate of the PASMCs was altered in a concentration-dependent manner by troglitazone in the cells cultured in GM under hypoxic conditions (Fig. 2A). The cell number of PASMCs treated with $0.5 \mu \mathrm{M}$ troglitazone was reduced to $93.3 \pm 1.2 \%$ compared with that of the PASMCs not treated with troglitazone (considered as 100\%). The percentage cell number of PASMCs cultured with troglitazone was $91 \pm 2.7 \%$ with $1 \mu \mathrm{M}$ of troglitazone, $91.1 \pm 3.5 \%$ with $2 \mu \mathrm{M}$, $93.5 \pm 2.8 \%$ with $5 \mu \mathrm{M}, 84.3 \pm 4.2$ with $10 \mu \mathrm{M}, 72 \pm 5.8 \%$ with 


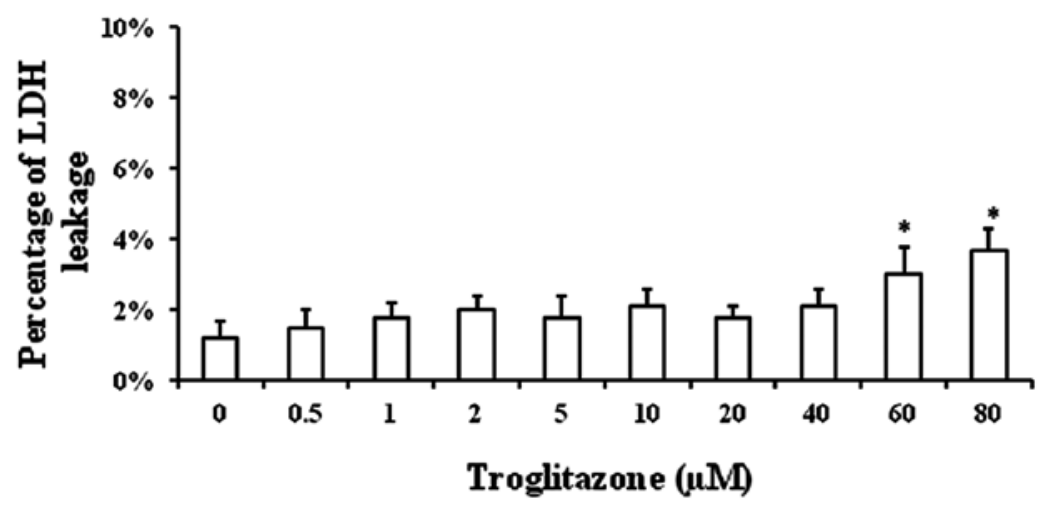

Figure 1. Cytotoxicity of various concentrations of troglitazone towards pulmonary artery smooth muscle cells (PASMCs). PASMCs were cultured in growth medium (GM) supplemented with troglitazone at $37^{\circ} \mathrm{C}$ in an incubator under normoxic conditions for $48 \mathrm{~h}$. The toxicity of troglitazone significantly increased when its concentration was $>60 \mu \mathrm{M}$. (" $\mathrm{P}<0.05$ vs. GM with $0 \mu \mathrm{M}$ troglitazone). The experiment was performed in triplicate.
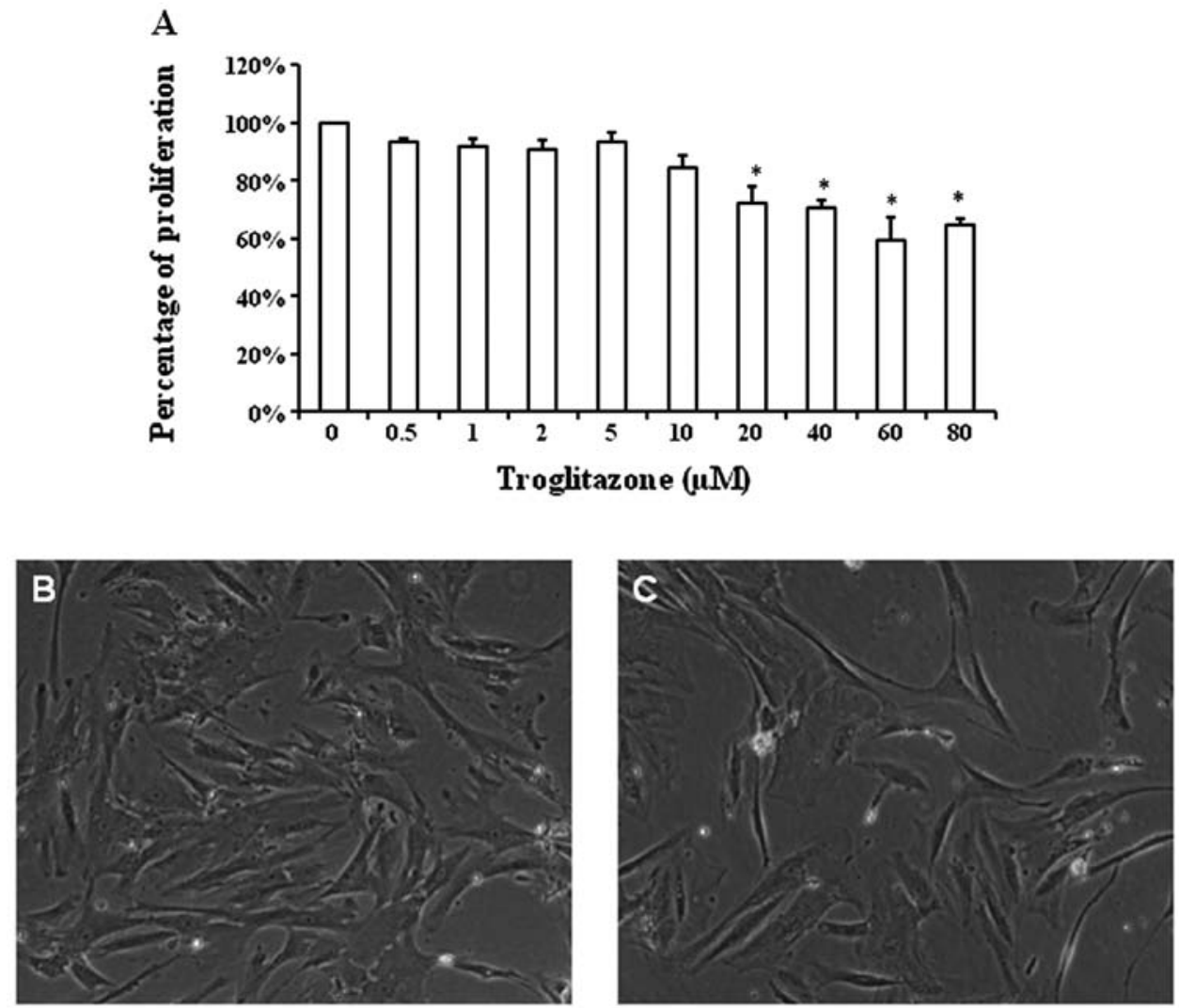

Figure 2. (A) Effects of various concentrations of troglitazone on the proliferation rate of pulmonary artery smooth muscle cells (PASMCs). PASMCs were cultured in growth medium (GM) supplemented with troglitazone under hypoxic conditions for $72 \mathrm{~h}$. (B) Typical images of PASMCs cultured in GM only; (C) PASMCs cultured in GM supplemented with $20 \mu \mathrm{M}$ troglitazone; (magnification, $\mathrm{x} 100)$. ("P<0.05 vs. GM with $0 \mu \mathrm{M}$ troglitazone). The experiment was performed at least in triplicate.

$20 \mu \mathrm{M}, 70.4 \pm 3 \%$ with $40 \mu \mathrm{M}, 59.3 \pm 8.3 \%$ with $60 \mu \mathrm{M}$ and $64.6 \pm 2.1 \%$ with $80 \mu \mathrm{M}$ troglitazone. Starting at the concentratikno of $20 \mu \mathrm{M}$, troglitazone significantly reduced the proliferation of PASMCs under hypoxic conditions $(\mathrm{P}<0.05)$.

Typical images of PASMC density following culture in GM with or without troglitazone are shown in Fig. 2B and C. Starting at the concentration of $20 \mu \mathrm{M}$, troglitazone significantly reduced the PASMC proliferation rate. Thus, we selected the concentration of $20 \mu \mathrm{M}$ troglitazone for the remaining experiments.
Troglitazone increases PTEN gene expression. Troglitazone significantly increased PTEN gene expression by $2.4 \pm 0.1$-fold at $2 \mathrm{~h}$ as compared with the baseline levels $(\mathrm{P}<0.05)$ under hypoxic conditions. Upregulated PTEN gene expression was maintained up to $8 \mathrm{~h}(1.7 \pm 0.02$-fold, $\mathrm{P}<0.05)$ (Fig. 3A).

Troglitazone does not alter gene expression of AKT-1 and $A K T-2$. Troglitazone did not significantly alter the gene expression of AKT-1 and AKT-2 in the PASMCs between any 2 time points (Fig. 3B and C). 

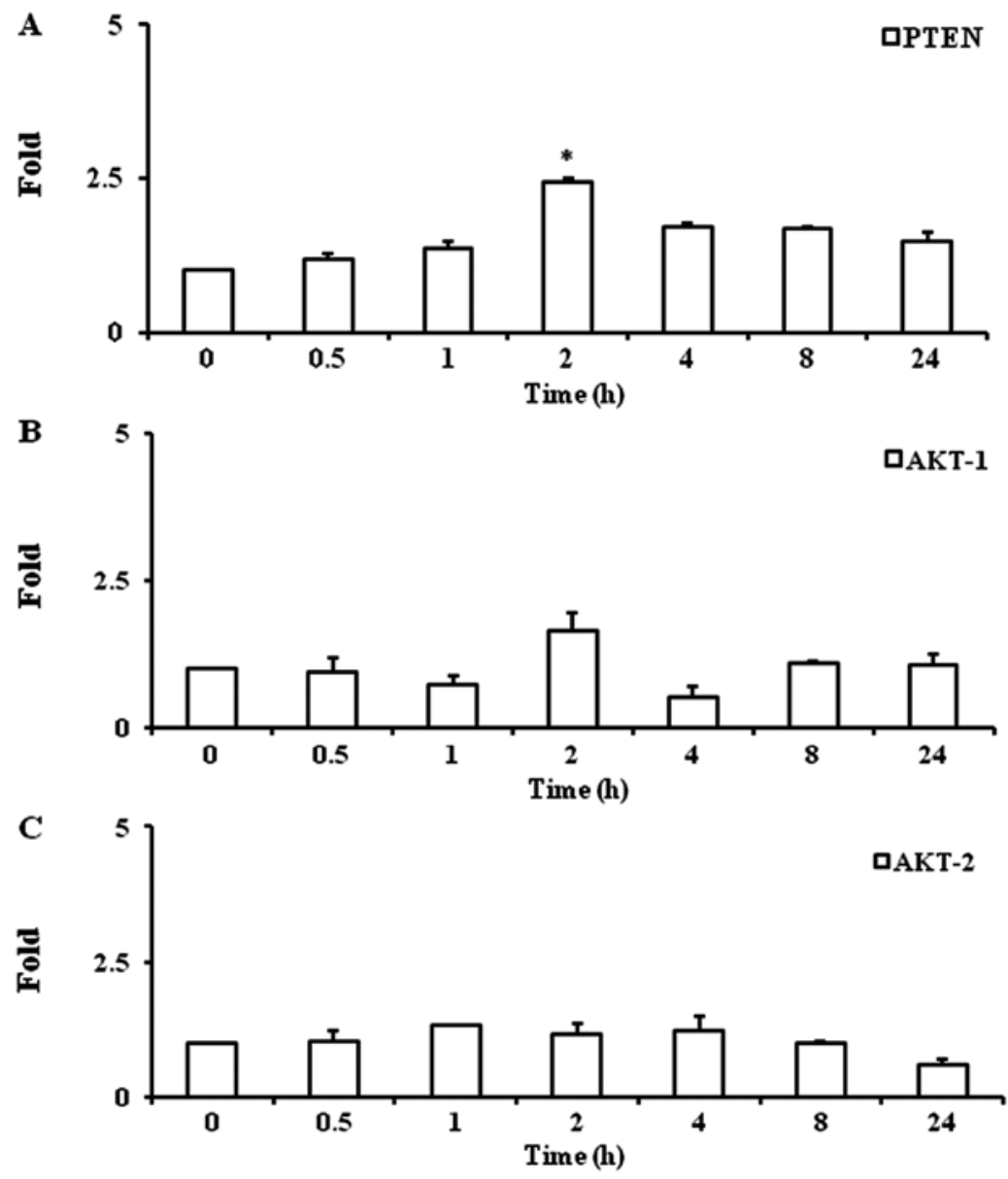

Figure 3. Effects of troglitazone on the expression of phosphatase and tensin homologue deleted on chromosome 10 (PTEN), AKT-1 and AKT-2.(A) Troglitazone significantly increased the gene expression of PTEN in pulmonary artery smooth muscle cells (PASMCs) cultured in growth medium (GM) supplemented with troglitazone under hypoxic conditions starting at $2 \mathrm{~h}$; this effect lasted up to $8 \mathrm{~h}($ ("P $<0.05$ vs. any other time point). Troglitazone did not significantly alter (B) AKT-1 and (C) AKT-2 gene expression in PASMCs cultured in GM under hypoxic conditions. The experiment was performed in triplicate.

Western blot analysis of cultured PASMCs supplemented with troglitazone. Troglitazone increased PTEN protein expression in PASMCs cultured under hypoxic conditions for $2 \mathrm{~h}$. A significantly increased PTEN protein expression level was observed when the cells were treated with troglitazone at concentrations between 20-80 $\mu \mathrm{M}$, while no significant changes in p-AKT and AKT expression were observed (Fig. 4A). The PASMCs were then cultured with $20 \mu \mathrm{M}$ troglitazone for $24 \mathrm{~h}$ and DMSOtreated cells (without troglitazone) were used as controls, since troglitazone was diluted in DMSO. In the cells treated with troglitazone, a significantly increased PTEN protein expression was observed within $2 \mathrm{~h}$ compared with the cells treated with DMSO alone. The highest PTEN protein expression level was observed within $4 \mathrm{~h}$ after the addition of troglitazone, which was significantly higher than that at $0.5 \mathrm{~h}$ (Fig. 4B). Troglitazone also progressively reduced p-AKT expression within $2 \mathrm{~h}$; these levels were significantly lower than those from the cells treated with DMSO alone.

To determine whether the upregulated PTEN protein expression induced by troglitazone was mediated by the PPAR $\gamma$ signaling pathway and inhibited by the PTEN inhibitor, PASMCs were pre-treated with $2.5 \mu \mathrm{M} \mathrm{bpV(HOpic)} \mathrm{(a} \mathrm{PTEN}$ inhibitor) or $1 \mu \mathrm{M} \mathrm{GW} 9662$ (PPAR $\gamma$ antagonist) for $1 \mathrm{~h}$ prior to the addition of troglitazone. It was found that the upregulated protein expression of PTEN was reduced by pre-treatment with bpV(HOpic) and GW9662 for up to $24 \mathrm{~h}$ (Fig. 4C and D).

Effects of bpV(HOpic) and GW9662 on proliferation of PASMCs treated with troglitazone. Typical images of the PASMC growth profile are shown in Fig. 5A-G. Troglitazone significantly reduced the proliferation rate of the PASMCs under hypoxic conditions. $\mathrm{bpV}(\mathrm{HOpic})$ was used to determine whether the PTEN inhibitor reversed the inhibitory effects of troglitazone on PASMC proliferation. It was found that troglitazone did not reduce the proliferation rate of the PASMCs that were pre-treated with $\mathrm{bpV}(\mathrm{HOpic})$. These results suggest that troglitazone inhibits PASMC proliferation by upregulating PTEN expression, which may be reversed by the PTEN inhibitor (Fig. 5H).

GW9662 was also used to determine whether the upregulation in PTEN expression stimulated by troglitazone was mediated by the PPAR $\gamma$ signaling pathway. It was found that GW9662 reversed the inhibitory effects of troglitazone on PASMC proliferation. These results suggest that troglitazone upregulates PTEN expression through the PPAR $\gamma$ signaling pathway (Fig. 5). 

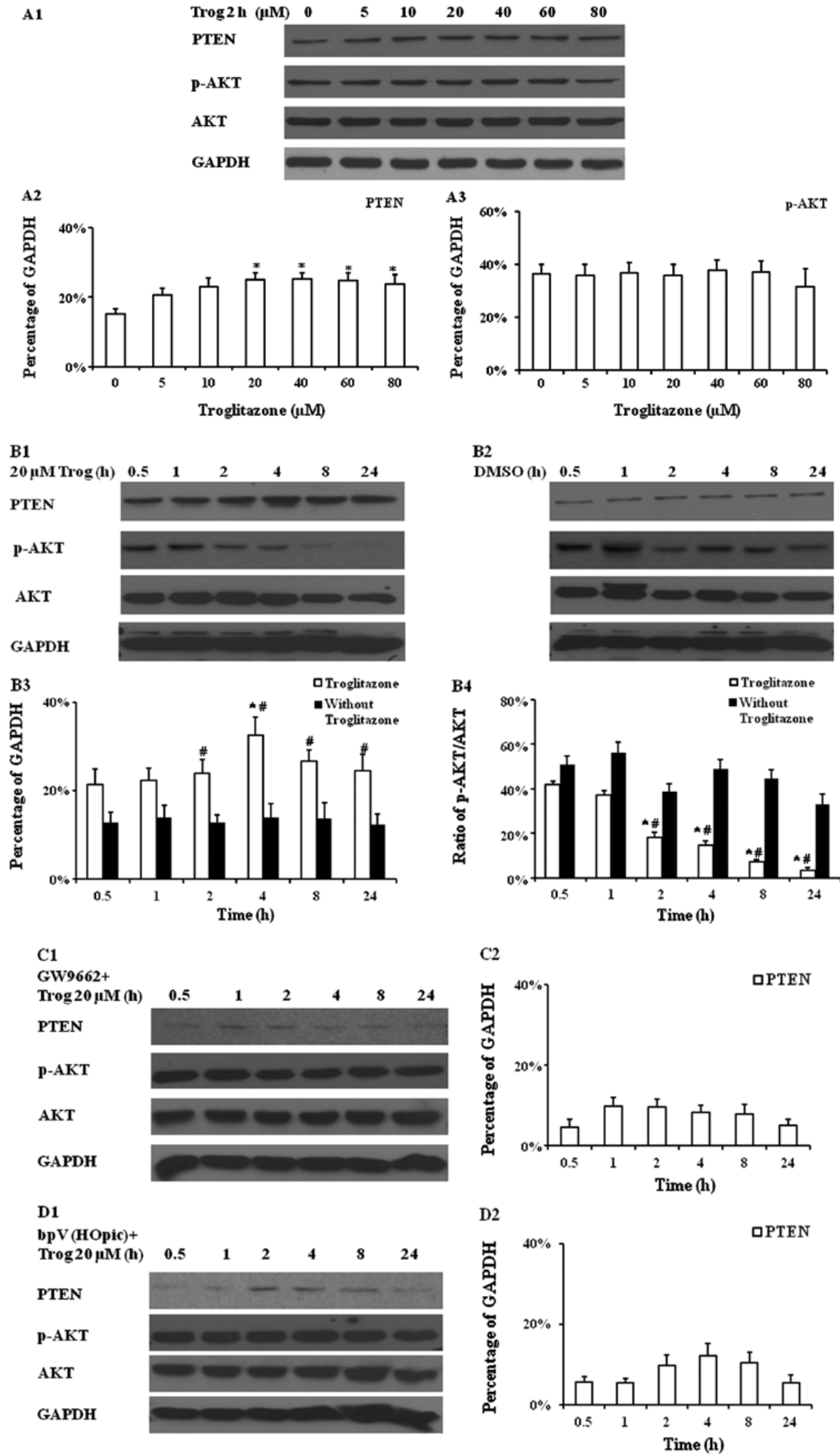

Figure 4. Western blot analysis of pulmonary artery smooth muscle cells (PASMCs) cultured in GM supplemented with troglitazone for $2 \mathrm{~h}$ under hypoxic conditions. (A1-3) Effects of various concentrations of troglitazone on the protein expression of phosphatase and tensin homologue deleted on chromosome 10 (PTEN) and p-AKT in PASMCs cultured under hypoxic conditions. A significantly increased PTEN protein expression was observed with concentrations of troglitazone starting from $20 \mu \mathrm{M}$, while no significant change in phospho-AKT (p-AKT) expression was observed. ("P< $<0.05$ vs. $0 \mu \mathrm{M}$ troglitazone). (B1-4) Effects of troglitazone on PTEN protein expression and p-AKT expression in PASMCs cultured with $20 \mu \mathrm{M}$ troglitazone under hypoxic conditions for various periods of time. PASMCs treated with DMSO (without troglitazone) were used as controls. Troglitazone significantly increased PTEN protein expression starting from $2 \mathrm{~h}$ as compared with DMSO treatment only, while troglitazone progressively reduced p-AKT expression. ( $\mathrm{P}<0.05$ vs. $0.5 \mathrm{~h}$ troglitazone; ${ }^{*} \mathrm{P}<0.05$ vs. without troglitazone at $2,4,8$ and 24 h). (C1-2) GW9662 (PPAR $\gamma$ antagonist) inhibited PTEN protein expression in PASMCs. GW9662 was added $1 \mathrm{~h}$ prior to the addition of $20 \mu \mathrm{M}$ troglitazone. (D1-2) bpV(HOpic) (PTEN inhibitor) inhibited PTEN protein expression in PASMCs. Trog, troglitazone. The experiment was performed in duplicate. 


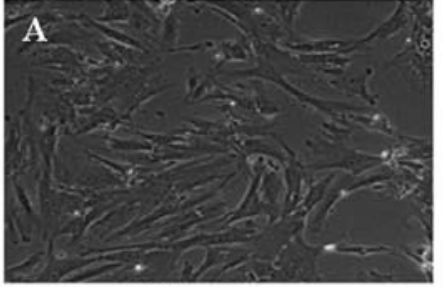

GM

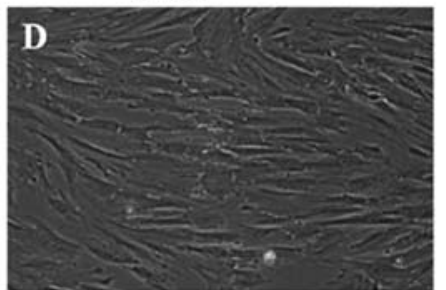

GW9662

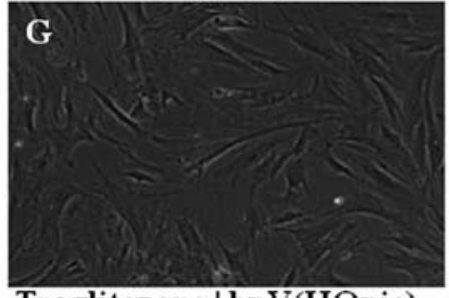

Troglitaz one+bpV(HOpic)

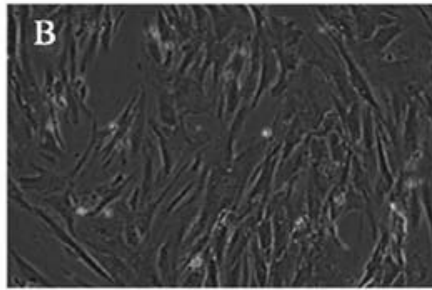

DMSO

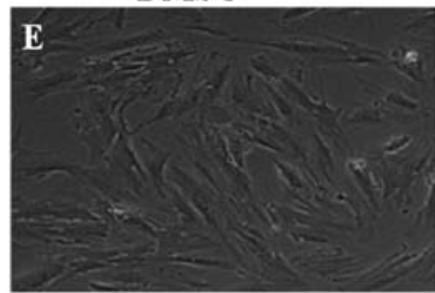

bpV(HOpic)

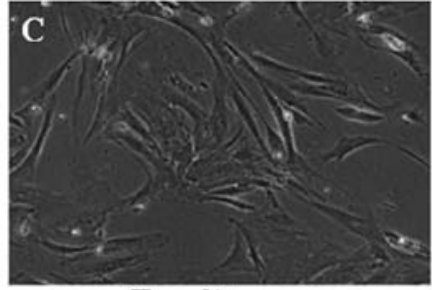

Troglitaz one

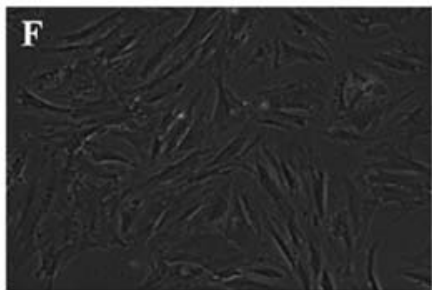

Troglitazone+GW9662

$\mathrm{H}$

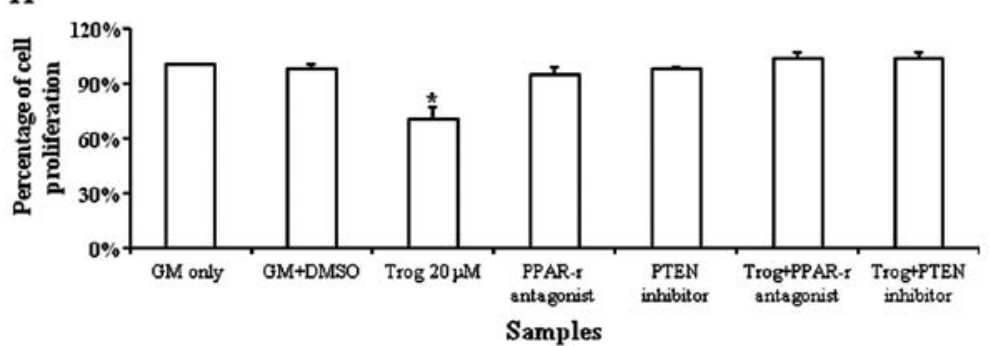

Figure 5. Growth profile of pulmonary artery smooth muscle cells (PASMCs) cultured in growth medium (GM) supplemented with troglitazone, GW9662 and $\mathrm{bpV}$ (HOpic) for $72 \mathrm{~h}$ under hypoxic conditions. Phase contrast images of (A) PASMCs cultured in GM only, (B) GM supplemented with DMSO, (C) GM supplemented with troglitazone, (D) GW9662, (E) bpV(HOpic), (F) troglitazone + GW9662, (G) troglitazone + bpV(HOpic). (H) Quantification of PASMCs treated with troglitazone, GW9662 and bpV(HOpic). The cell number of PASMCs cultured in GM was regarded as $100 \%$. "P<0.05 vs. any other samples. Magnification, $\mathrm{x} 100$; Trog, troglitazone. The experiment was performed in triplicate.

Troglitazone increases caspase-3, -8 and -9 activities. A significantly increased caspase-3 activity was observed when the PASMCs were cultured in GM $(6.5 \pm 0.15 \mathrm{FI} / \mathrm{min} / \mathrm{ml})$ supplemented with troglitazone for 8 h (Fig. 6A). Similarly, a significant increase in caspase- 8 and -9 activities was observed when the PASMCs were cultured in GM $(5.3 \pm 0.15$ and $6.1 \pm 0.27 \mathrm{FI} / \mathrm{min} / \mathrm{ml}$ ) supplemented with troglitazone for $8 \mathrm{~h}$ (Fig. 6B and C).

Troglitazone increases the apoptosis of PASMCs under hypoxic conditions. TUNEL staining revealed that the apoptosis of PASMCs cultured in BM increased after $72 \mathrm{~h}$ under hypoxic conditions (Fig. 6D and E). Quantification of TUNEL ${ }^{+}$ cells suggested that troglitazone significantly increased the apoptotic PASMC number compared with the cells cultured in $\mathrm{BM}$ alone $(\mathrm{P}<0.05)$.

\section{Discussion}

The present study demonstrates that troglitazone, a highaffinity synthetic ligand of PPAR $\gamma$ upregulates PTEN gene and protein expression levels in PASMCs under hypoxic conditions in a concentration-dependent manner. In addition, we demonstrate that troglitazone increases the apoptosis of PASMCs under hypoxic conditions.

Pulmonary vascular remodelling in pulmonary arterial hypertension is characterized by changes in pulmonary vascular structure $(1,2)$. This is partially caused by an imbalance in PASMC proliferation and apoptosis (10). The increased proliferation and decreased apoptosis of PASMCs result in the thickening of the pulmonary vasculature, which subsequently increases pulmonary vascular resistance and pulmonary arterial pressure (11).

Our results demonstrated that troglitazone at the concentration of 20-80 $\mu \mathrm{M}$ effectively inhibited PASMC proliferation under hypoxic conditions. The anti-proliferative effects of troglitazone may be related to its role in the upregulation of PTEN and the induction of the apoptosis of PASMCs under hypoxic conditions. PPAR $\gamma$ expression has been found in pulmonary vascular endothelial cells and SMCs $(12,13)$. However its expression is reduced in lung vascular cells of rats with pulmonary hypertension and in patients with advanced primary or secondary pulmonary hypertension (12). The targeted depletion of PPAR $\gamma$ from SMCs has been shown to result in spontaneous pulmonary hypertension in mice (4). However, the activation of PPAR $\gamma$ with thiazolidinediones attenuates vascular remodeling and pulmonary hypertension caused by monocrotaline (14) or hypobaric hypoxia (15) in rats. Thiazolidinediones also reduce pulmonary hypertension in ApoE-deficient mice fed high-fat diets (16) and attenuate hypoxia-induced pulmonary hypertension and Nox4 expression and activity in mice (5).

However, the role of PPAR $\gamma$ in the regulation of PTEN expression of PASMCs under hypoxic conditions has not 


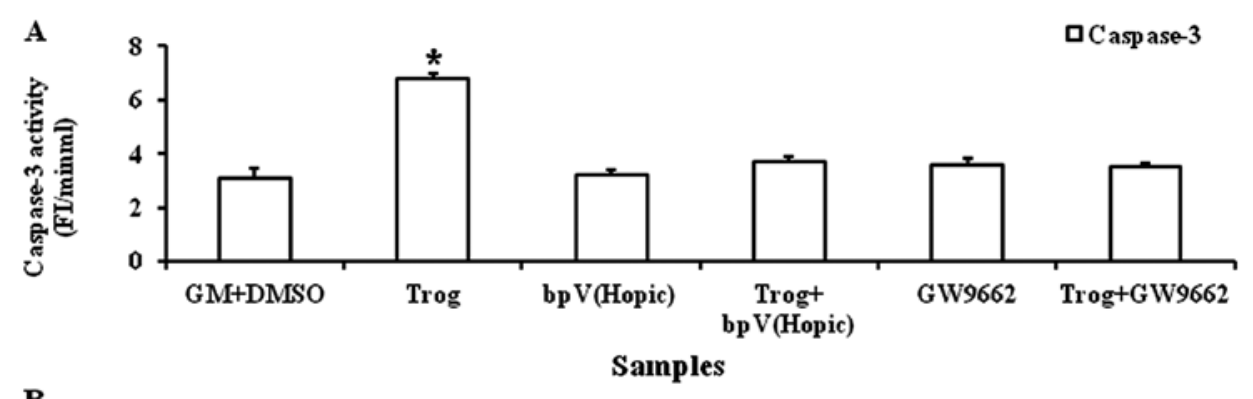

B

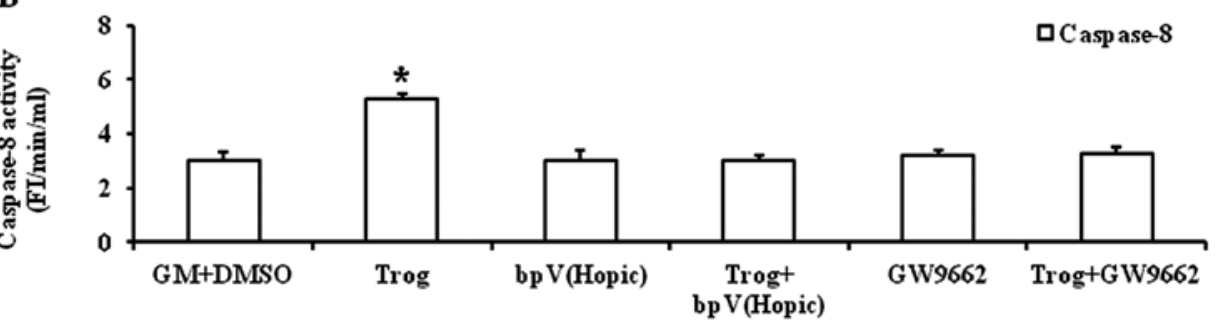

Samples

C

造

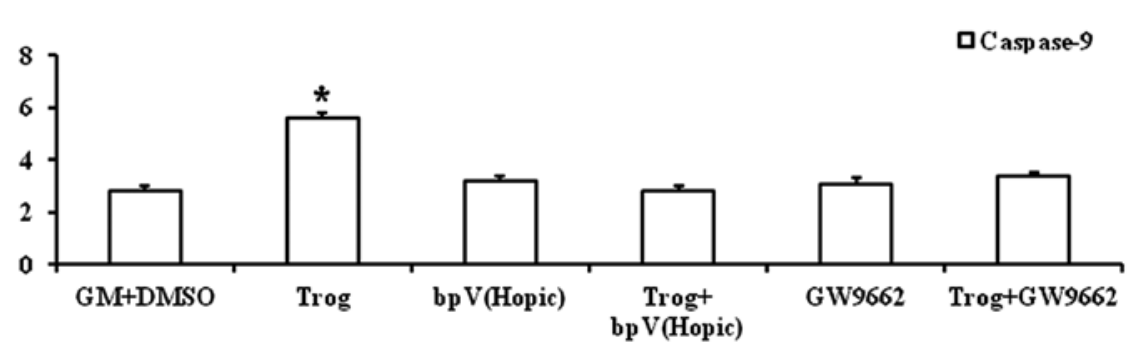

Samples
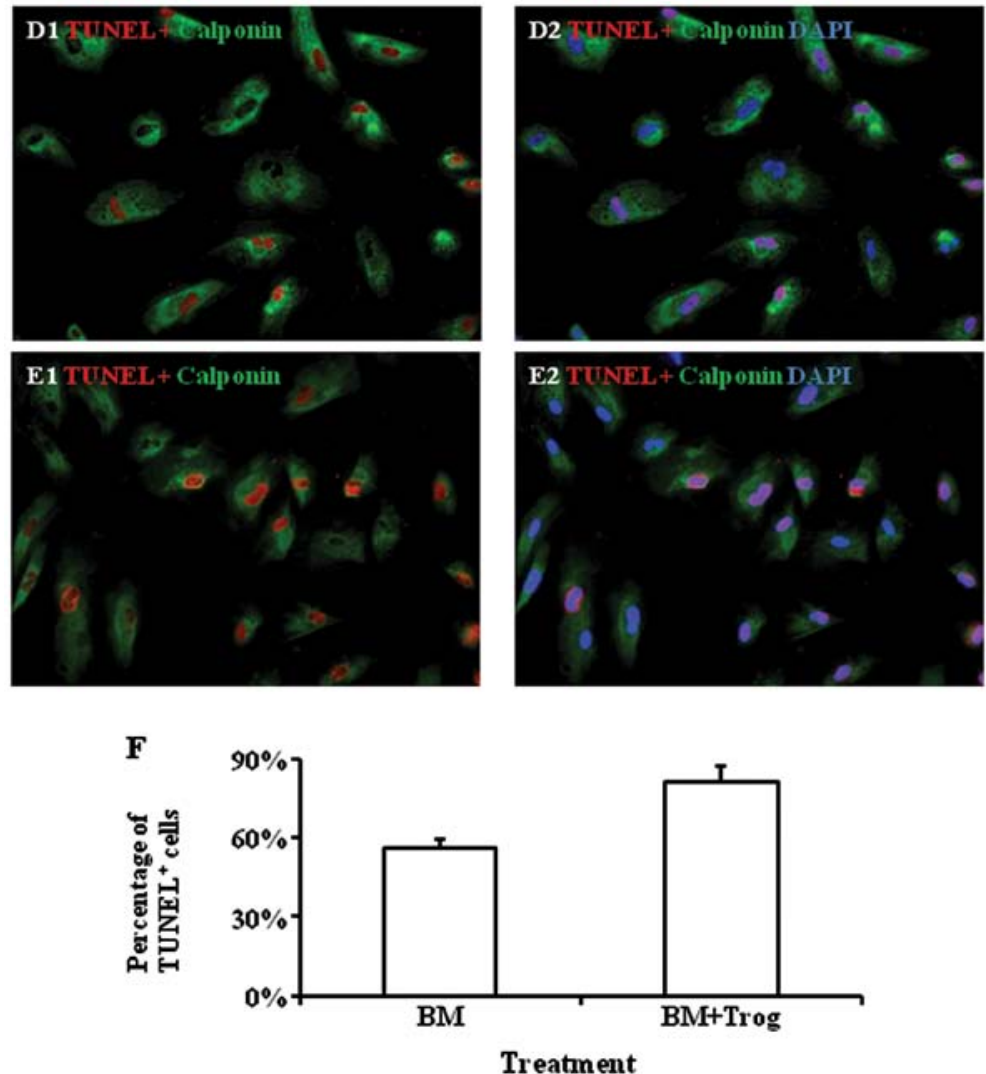

Figure 6. Troglitazone increases caspase, $-3,-8$ and -9 activity. Troglitazone increased (A) caspase-3, (B) caspase- 8 and (C) caspase- 9 activity in pulmonary artery smooth muscle cells (PASMCs) cultured under hypoxic conditions after $72 \mathrm{~h}$ ("P $<0.05$ vs. all other samples). TUNEL staining to detect the apoptosis of PASMCs cultured in basal medium (BM) under hypoxic conditions for $72 \mathrm{~h}$. (D1 and E1) The apoptotic nuclei of the PASMCs are shown in red colour. (D2 and E2) The cells were counterstained with DAPI to show cell nuclei. Magnification, x100. (F) Quantification of TUNEL ${ }^{+}$cells suggested that troglitazone significantly increased the apoptotic PASMC number as compared with those cultured in BM only. ("P<0.05 vs. BM). Trog, troglitazone. The experiment was performed in duplicate. 
been examined yet. Our results demonstrate that PPAR $\gamma$ upregulates PTEN gene and protein expression levels. Studies have shown that PPAR $\gamma$ agonists upregulate the transcription of PTEN in cancer cells. PPAR $\gamma$ agonists have been used as tumor suppressors in breast cancer by upregulating PTEN gene expression (17), while cells lacking PTEN or PPAR $\gamma$ are unable to induce PTEN-mediated cellular events in the presence of lovastatin or rosiglitazone. Zhang et al (7) showed that PTEN is required for the rosiglitazone-induced inhibition of BEL-7404 cells. Rosiglitazone upregulated PTEN expression in a concentration- and time-dependent manner, which was mediated by PPAR $\gamma$. Furthermore, PTEN overexpression resulted in the inhibition of BEL-7404 cell migration, and PTEN knockdown blocked the effects of rosiglitazone on cell migration.

It is known that PPAR $\gamma$ agonists can stimulate the production and secretion of ApoE, which has anti-proliferative effects on human PASMCs (4). Nisbet et al (5) found that rosiglitazone attenuated hypoxia-induced pulmonary vascular remodelling and hypertension by suppressing oxidative and proliferative signals. They found that rosiglitazone attenuated the reduction in PTEN expression. However, the present study demonstrates that troglitazone upregulates PTEN gene and protein expression levels in human PASMCs under hypoxic conditions. This may provide new insight into the mechanisms behind the anti-proliferative effects of PPAR $\gamma$ on PASMCs under hypoxic conditions.

The data from the present study also suggest that troglitazone increases the apoptosis of PASMCs under hypoxic conditions. It is known that chronic hypoxia can prolong the growth of human vascular SMCs by inducing telomerase activity and telomere stabilization (18). The upregulation of PTEN negatively regulates the AKT/PKB signaling pathway and leads to a decrease in p-AKT levels and, consequently, to a decrease in AKT-mediated proliferation (19). Thus, a reduced p-AKT expression in PASMCs was found after the addition of troglitazone in this study. By reducing the cellular levels of $\mathrm{p}$-AKT, PTEN downregulates cell division and increases apoptosis. This may result in increased activities of caspase- $3,-8$ and -9 , thus inducing the apoptosis of PASMCs under hypoxic conditions.

In conclusion, the present study highlights that troglitazone increases PTEN gene expression at the transcriptional level under hypoxic conditions in a concentration-dependent manner. Troglitazone increases the apoptosis of PASMCs under hypoxic conditions. The increased PTEN expression and apoptosis of PASMCs provide new insight into the mechanisms behind the anti-proliferative effects of troglitazone on PASMCs.

\section{References}

1. McLaughlin VV, Archer SL, Badesch DB, et al: ACCF/AHA 2009 expert consensus document on pulmonary hypertension: a report of the American College of Cardiology Foundation Task Force on Expert Consensus Documents and the American Heart Association: developed in collaboration with the American College of Chest Physicians, American Thoracic Society, Inc., and the Pulmonary Hypertension Association. Circulation 119: 2250-2294, 2009.
2. Pietra GG, Edwards WD, Kay JM, et al: Histopathology of primary pulmonary hypertension. A qualitative and quantitative study of pulmonary blood vessels from 58 patients in the National Heart, Lung, and Blood Institute, Primary Pulmonary Hypertension Registry. Circulation 80: 1198 -1206, 1989.

3. Nakaoka T, Gonda K, Ogita T, et al: Inhibition of rat vascular smooth muscle proliferation in vitro and in vivo by bone morphogenetic protein-2. J Clin Invest 100: 2824-2832, 1997.

4. Hansmann G, de Jesus Perez VA, Alastalo TP, et al: An antiproliferative BMP-2/PPARgamma/apoE axis in human and murine SMCs and its role in pulmonary hypertension. J Clin Invest 118: 1846-1857, 2008.

5. Nisbet RE, Bland JM, Kleinhenz DJ, et al: Rosiglitazone attenuates chronic hypoxia-induced pulmonary hypertension in a mouse model. Am J Respir Cell Mol Biol 42: 482-490, 2010.

6. Lee KS, Park SJ, Hwang PH, Yi HK, Song CH, Chai OH, Kim JS, Lee MK and Lee YC: PPAR-gamma modulates allergic inflammation through up-regulation of PTEN. FASEB J 19: 1033-1035, 2005.

7. Zhang W, Wu N, Li ZX, Wang LY, Jin JW and Zha XL: PPARgamma activator rosiglitazone inhibits cell migration via upregulation of PTEN in human hepatocarcinoma cell line BEL-7404. Cancer Biol Ther 5: 1008-1014, 2006.

8. Ye L, Haider KhH, Esa WB, et al: Liposome-based vascular endothelial growth factor-165 transfection with skeletal myoblast for treatment of ischaemic limb disease. J Cell Mol Med 14: 323-336, 2010.

9. Ye L, Lee KO, Su LP, et al: Skeletal myoblast transplantation for attenuation of hyperglycaemia, hyperinsulinaemia and glucose intolerance in a mouse model of type 2 diabetes mellitus. Diabetologia 52: 1925-1934, 2009.

10. Zhang S, Fantozzi I, Tigno DD, et al: Bone morphogenetic proteins induce apoptosis in human pulmonary vascular smooth muscle cells. Am J Physiol Lung Cell Mol Physiol 285: L740-L754, 2003.

11. Barst RJ, McGoon M, Torbicki A, Sitbon O, Krowka MJ, Olschewski H and Gaine S: Diagnosis and differential assessment of pulmonary arterial hypertension. J Am Coll Cardiol 43: 40S-47S, 2004

12. Ameshima S, Golpon H, Cool CD, et al: Peroxisome proliferatoractivated receptor gamma (PPARgamma) expression is decreased in pulmonary hypertension and affects endothelial cell growth. Circ Res 92: 1162-1169, 2003.

13. Michalik L, Auwerx J, Berger JP, et al: International Union of Pharmacology. LXI. Peroxisome proliferator-activated receptors. Pharmacol Rev 58: 726-741, 2006.

14. Matsuda Y, Hoshikawa Y, Ameshima S, et al: Effects of peroxisome proliferator-activated receptor gamma ligands on monocrotaline-induced pulmonary hypertension in rats. Nihon Kokyuki Gakkai Zasshi 43: 283-288, 2005 (In Japanese).

15. Crossno JT Jr, Garat CV, Reusch JE, et al: Rosiglitazone attenuates hypoxia-induced pulmonary arterial remodeling. Am J Physiol Lung Cell Mol Physiol 292: L885-L897, 2007.

16. Hansmann G, Wagner RA, Schellong S, et al: Pulmonary arterial hypertension is linked to insulin resistance and reversed by peroxisome proliferator-activated receptor-gamma activation. Circulation 115: 1275-1284, 2007.

17. Teresi RE, Shaiu C, Chen C, Chatterjee K, Waite KA and Eng C: Increased PTEN expression due to transcriptional activation of PPARgamma by Lovastatin and Rosiglitazone. Int J Cancer 118: 2390-2398, 2006.

18. Minamino T, Mitsialis SA and Kourembanas S: Hypoxia extends the life span of vascular smooth muscle cells through telomerase activation. Mol Cell Biol 21: 3336-3342, 2001.

19. Maehama T and Dixon JE: The tumor suppressor, PTEN/ MMAC1, dephosphorylates the lipid second messenger, phosphatidylinositol 3,4,5-trisphosphate. J Biol Chem 273: 13375-13378, 1998. 